\title{
DIGITALIZATION IN THE HUMANITIES - BRIEF OVERVIEW WITH THE SPECIAL ATTENTION TO THE SITUATION IN SERBIA
}

\section{Ema Miljković ${ }^{1}$}

Department of History, Faculty of Philosophy, Niš University

Received: 16.09 .2015

Accepted: 27.09.2015

\author{
Original scientific paper
}

UDC: $3: 004(497.11)$

\begin{abstract}
The humanities have definitely entered the new phase regarding the research method. One of the new approaches is certainly digitalization of the available material and creation of various interfaces for its usage. The new method has gained its pace first in the United States and then also in the Western Europe. As for Serbia, some significant steps have been made into that direction, although there is still lot of things to be done.

Key words: Humanities, Digitalization, Methodology, Research Corpus, Archives, Libraries
\end{abstract}

\section{INTRODUCTION}

The fast development of the technical and technological sciences has brought the changes to the almost all aspect of live, including science and research. And by the science we do not only mean the general meaning of the notion (e.g. chemistry, biology, genetics, etc.) or informatics and computer sciences, which goes without saying, but also in the field of the humanities. As it can be expected, the lead in this new trend is in the hands of those countries who had already fulfill the task of general research in the field of history, archeology, literature, ethnology, anthropology, etc. In search for a new method of research, and also in need to open broader questions they came to the solution with a name of digitalization.

Of course, digitalization cannot be the answer by itself. In order to proceed to digitalization, several conditions have to be met. Those conditions could be briefly summarized into two:

The digitalization is multidisciplinary and multitasking discipline; it encompasses experts both from the field of humanities and computer sciences;

There has to be a good corpus to be digitalized.

Although very clear by themselves, let us briefly elaborate on the above mentioned conditions:

Researcher for the field of humanities knows which question would like to ask but cannot create all by himself or herself interface to do it. Thus, he need a help from an expert in computer sciences, who could fulfill his/hers demands.

If the researcher from the field of humanities really wants to pose broader questions, to establish links, time frames, geographical identification, etc. which all could be established by well created interface, he/ she has to have a corpus that can answer those serious questions. It is impossible to make conclusion on the basis of one document, letter, manuscript It has to be a significant corpus in order to get the job well done!

\section{I}

In her article dedicated on the digitalization in the humanities, the New York Times famous reporter/researcher Patricia Cohen (2010) states that „A history of the humanities in the 20th century could be chronicled in "isms" - formalism, Freudianism, structuralism, postcolonialism - grand intellectual cathedrals from which assorted interpretations of literature, politics and culture spread. The next big idea in language, history and the arts? Data.

\footnotetext{
${ }^{1}$ Correspodence to:

Ema Miljković, PhD, Department of History, Faculty of Philosophy, Niš University

E-mail: ema.miljkovic@ffilfak.ni.ac.rs
} 
Members of a new generation of digitally savvy humanists argue it is time to stop looking forinspiration in the next political or philosophical "ism" and start exploring how technology is changing our understanding of the liberal arts. This latest frontier is about method, they say,using powerful technologies and vast stores of digitized materials that previous humanities scholars did not have."

(http://www.nytimes.com/2010/11/17/arts/17digital. html? r=0)

She based her thinking having in prospect scientific project in the university centers in northern America, where digitalization was important part of the research process in the humanities even a decade ago.

The Western European researchers also try to keep a pace with their American colleagues, thus the projects of the kind are not rare at the western European universities as well. One of the good examples is the project „Reassembling the Republic of Letters 15th -18 th century", funded by COST programme, including the researchers from almost all European countries. (http://www.republicofletters.net)

As stated in the programme manifesto, the aim of this project is to „The early modern communications revolution allowed scholars to scatter correspondence across Europe, knitting together the international, knowledge-based civil society crucial to that era's intellectual breakthroughs and formative for many of modern Europe's values and institutions. The current IT revolution provides means for reassembling and disseminating this precious literary heritage for the first time while fostering new forms of scholarly cooperation. In pursuit of these aims, this Action will (1) undertake a historiographical reconsideration of the place of the Republic of Letters in Europe's cultural formation; (2) coordinate the intensive discussion amongst librarians and archivists, IT experts, and scholars needed to plan a state-of-the-art digital system within which to collect a pan-European pool of highly granular data on the Republic of Letters; (3) design tools for navigating, analysing and visualising this huge pool of data, and for facilitating new forms of international and interdisciplinary scholarly collaboration, thereby consolidating a new virtual Republic of Letters; and (4) experiment with using this system to engage the broader public with the cuttingedge technical and scholarly work on this key phase of European cultural and intellectual integration." (Ibid)

One of the best examples of the digitalized database which is of immense importance as for the above mentioned project as for wider research is the English
Moderne Letters Online (EMLO) database, created by the Cultures of Knowledge project, and funded also by the The Andrew W. Mellon Foundation. As it was stated in the database home page this is ,combined finding and editorial interface for basic description of early modern correspondence“". (www.emlo. bodleian.ox.ac.uk)

This database encompasses the following: 95227 letters, 31 catalogues, 20660 peoples, 5125 locations, 269 repositories, 82703 letters versions, 59502 images, 38540 comments and 67922 related sources. (Ibid) The well designed searching engine contains following fields: peoples, years (from - to), places, content, and catalogue. Just for instance, if a researcher types Constantinople in the field named places, he would get a list of 34 results, i.e. letters, of which first was written in 1586 by William Harborne, first English ambassador in the Ottoman Empire, just at the time when the diplomatic and trade relations between two countries had begun to be developing. (Ibid)

\section{II}

As for situation in the Republic of Serbia, regarding the digitalization as the research method in the humanities, some efforts has been made, some developments acieved, but there is still a lot of things to be done in order to reach the level of the most developed historiographies such as British, for instance.

In the Serbian archives, libraries, museums and other places of cultural significanse there is lotof documents, textual data, image data and other values of the national heritage. The great number of those documents are of immens importance, thus the attention of the researchers in order to resent them to professional and even wider public. On the other hand, those documents can be easily destroyed by handling them directly.

The modern computer sciences enable to organize the system of information for such data, creating this way huge possibilities in keeping, preserving, researching, and presentation of the selected documents to the professioanl and scientific oriented public. Also, we should bare in mind the fact that the recent comparatively low prices of the computer equimpment, softwares and usage of the computer nets, make possible wider usage of the informatic technologies, in all scientific areas, and in the humanities as well.

Paying attention to what was said above, several institutions in the Republic of Serbia, as far as 1995 cooperate in several common projects of digitalization in the humanities. 
Those insitutions are: Mathematical Institute of Serbian Academy of Sceinces and Arts, Faculty of Mathematics Belgrade University, Archeological institute of Serbian Academy of Sciences and Arts, Institute of Musicology of Serbian Academy of Scences and Artss, Museuem of the city of Belgrade, Museum Nikola Tesla, and in some aspects of the project are also included The National Museum of Serbia, The State Archive of Serbia, The Institute for Preservation of the Cultural Monuments of Republic of Serbia, The Historical Archive in Kotor and Institute for Film. All those projects are mainly founded by the state fonds. Howere, bearing in mind the accomplished results it coudl be said that the main input to realization of those projects was the enthusiasam of the coworkers themselves. (http://biba.rgf.bg.ac.rs:8005/print-tmx. xqy?pcreationid=1.2014.1.6\&qLng=sr)

In the words of main actors of the project themselves, as a result of this effort several objects have been established:

The overall aim for the digital library is to create a comprehensive and semanticallyinterconnected collection of retro-digitized books and other digital documents.

Objectives of the project include electronic archiving of old manuscripts and books, their publishing in electronic phototype form and finally presentation to the generalaudience. Our proposal is mathematically inclined, more specifically, the project isconcerned with digitization of old books and other manuscripts satisfying the followingcriteria:

1. Books and other manuscripts contained in Serbian public and semi-openlibraries. By a semi-open library we mean any departmental library and privatecollections of books.

2. Books and manuscripts selected for digitization should be related withmathematical sciences: mathematics, mechanics, astronomy, physics andmathematical geography.

3. Books considered for digitization had to be published before certain date in thepast. We have chosen for this date the beginning of the Second World War (1941).

4. Preference will be given to Serbian authors, or to written works related in someway to Balkan area. (Mijajlović, Ognjanović, Đorđević and Zečević, 2004)
It is also important to mention the establishment of the national Center for Digital Humanties, as well as of the journal called Journal of the National Center for Digital manities, which is, of course, availabe online. http://www.ncd.matf.bg.ac.rs/casopis/Sadrzaj.html There is also regual annual conference dedicated to this topic and the papers discuessed at this annual meeting have been published later in the special collection of essays. (http://www.ncd.org.rs/ncd_sr/ Events/NCDbeograd2015/ncd_call_2.pdf)

Faculty of Philology of the Belgrade University has began the project of digitalization of manuscripts of the famous writer Ivo Andrić (1892-1975). The writer's personal fond, property of the „Ivo Andrićc Endowmentand kept in the Archive of the Serbian Academy of Sciences and Arts had already been digitalized. The digitalized edition would be preserved in the digital library of the Faculty of Philology of the Belgrade University and at the free disposal to the users of the „Ivo Andrić“" Endowment. (http://www. politika.rs/rubrike/Kultura/Digitalizovan-licni-fondIve-Andrica.lt.html)

At the end it could be concluded that the digitalization in the humanities has been developing very fast thus making the research easier and faster. As for the situation in the Republic of Serbia, some steps had already been undertaken but there is still a lot of work for all of us, members of the academic community of the humanities, to be done.

\section{REFERENCES}

Cohen P. (2010). Digital Keyes for unlocking the Humanities ' Riches, http://www.nytimes.com/2010/11/17/arts/17digital. html? $\mathrm{r}=0$

Mijajlović, Ž., Ognjanović, Z., Đorđević, N., \& Zečević, T. (2004). Virtual Library - Data Base of Textual Data, Преглед НЦД 5 42-48.

http://biba.rgf.bg.ac.rs:8005/print-tmx.xqy?pcreationid=1.2014. $1.6 \& \mathrm{qLng}=\mathrm{sr}$

www.emlo.bodleian.ox.ac.uk

http://www.ncd.org.rs/ncd sr/Events/NCDbeograd2015/ncd call_2.pdf

http://www.ncd.matf.bg.ac.rs/casopis/Sadrzaj.html http://www.nytimes.com/2010/11/17/arts/17digital.html?_r=0 http://www.politika.rs/rubrike/Kultura/Digitalizovan-licnifond-Ive-Andrica.lt.html

http://www.republicofletters.net/ 